\title{
Seroprevalencia de infección por el virus de leucosis bovina durante 2015 en rodeos de cría de la Zona Deprimida del Río Salado, provincia de Buenos Aires, Argentina
}

\author{
Seroprevalence of bovine leukosis virus infection during 2015 in breeding herds \\ from Zona Deprimida del Río Salado, Province of Buenos Aires, Argentina
}

\author{
Panei $\mathbf{C J}^{1,2 *}$, Tassara F ${ }^{3,4}$, Pérez Aguirreburualde $\mathbf{M S}^{5}$, Echeverría MG ${ }^{1,2}$, \\ Galosi $\mathrm{CM}^{1,6}$, Torres $\mathrm{A}^{3}$, Silva HJE ${ }^{3}$
}

${ }^{1}$ Cátedra de Virología, Facultad de Ciencias Veterinarias, Universidad Nacional de La Plata; ${ }^{2}$ CONICET (Comisión Nacional de Investigaciones Científicas y Técnicas); ${ }^{3}$ Ministerio de Agroindustria de la provincia de Buenos Aires; ${ }^{4}$ Curso de Clínica y Sanidad en Rumiantes, Facultad de Ciencias Veterinarias, Universidad Nacional de La Plata; ${ }^{5}$ Unidad de Epidemiología, Instituto de Patobiología, INTA, CICVyA, Castelar, Buenos Aires; ${ }^{6} \mathrm{CIC}$ (Comisión de Investigaciones Científicas de la provincia de Buenos Aires).

${ }^{*}$ Correo electrónico del autor: javierpanei@fcv.unlp.edu.ar

\begin{abstract}
Resumen: La leucosis enzoótica bovina (LEB) es una enfermedad crónica, linfoproliferativa y altamente contagiosa producida por el virus de la leucosis bovina (VLB). La sangre es una fuente importante de infección, principalmente en la práctica veterinaria, considerando que solo 5 microlitros son suficientes para infectar a un bovino en forma experimental. La Zona Deprimida del Río Salado (ZDRS) está formada por poco más de 6 millones de hectáreas con una cantidad de terneros que representa el $16,05 \%$ de las existencias nacionales y el 34,03\% de las provinciales, convirtiéndose, de ese modo,en la principal zona criadora de terneros de Argentina. Los últimos estudios sobre seroprevalencia de infección por el VLB en rodeos de cría en la provincia de Buenos Aires se realizaron hace poco más de 20 años, obteniéndose valores inferiores al $2 \%$. En este trabajo se analizaron un total de 1957 bovinos de cría provenientes de 90 establecimientos, representando poco más del $85 \%$ de la superficie de la ZDRS, para determinar la presencia de anticuerpos contra el VLB mediante inmunodifusión en gel de agar, prueba utilizada en estudios epidemiológicos y en planes de erradicación de la enfermedad. La prevalencia en los establecimientos fue del 6,6\%, mientras que se obtuvo una seroprevalencia individual de $0,36 \%$. Debido a que la ZDRS es la de mayor productividad de terneros de cría en Argentina, es de sumo interés determinar la prevalencia de infección en esta región para establecer zonas libres de VLB.
\end{abstract}

Palabras clave: inmunodifusión en gel de agar, leucosis enzoótica bovina, Zona Deprimida del Río Salado

\begin{abstract}
Enzootic bovine leukemia (EBL) is a chronic, lymphoproliferative and highly contagious disease caused by the bovine leukemia virus (BLV). Blood is an important source of infection in veterinary practice; only 5 microliters are enough to infect a cow experimentally. The Zona Deprimida del Río Salado (ZDRS) is the main region of breeding calves in Argentina, covering more than 6 million hectares with $16 \%$ and $34 \%$ of the national and provincial calf stock, respectively. The latest reports of ELB prevalence in cow-calf farms in Buenos Aires province were performed more than 20 years ago with values lower than $2 \%$. In this work, 1957 bovines from 90 cow-calf farms representing just over $85 \%$ of the ZDRS were sampled to determine the presence of antibodies against BLV by agar gel immunodiffusion, a test used extensively in epidemiological studies, control and eradication of the disease. The prevalence in cow-calf farms was $6.6 \%$ while the individual prevalence was $0.36 \%$. Since ZDRS is the main area of breeder calfs production in Argentina, it is relevant to determine EBL prevalence in this region in order to detect $E B L$ free zones.
\end{abstract}

Key words: agar gel immunodiffussion, enzootic bovine leukemia, Zona Deprimida del Río Salado 


\section{Introducción}

La leucosis enzoótica bovina (LEB) es una enfermedad crónica, linfoproliferativa y altamente contagiosa producida por el virus de la leucosis bovina (VLB). La LEB se puede presentar de tres formas diferentes: una forma asintomática aleucémica $(A L)$, representada por un $65-70 \%$ de los animales positivos y caracterizada por una cantidad normal de linfocitos $B$ en la circulación sanguínea, una forma de linfocitosis persistente (LP), representada por el $25-30 \%$ de los animales positivos y caracterizada por un aumento sostenido de la cantidad absoluta de linfocitos B en la sangre y una presentación linfoproliferativa tumoral en forma de linfosarcoma o linfoma maligno, representada por el $1-5 \%$ de los animales positivos, con la presencia de masas sólidas tumorales, infiltrando diferentes órganos y tejidos (Burny et al., 1988).

La transmisión natural del virus se produce principalmente a través de las células infectadas con el provirus integrado (Mammerickx et al., 1987), detectándose altas copias de estos provirus en diferentes subpoblaciones de linfocitos (Panei et al., 2013). Por lo tanto, la sangre es una fuente importante de infección, principalmente en la práctica veterinaria (Hopkins \& DiGiacomo 1997; Kohara, 2006; Mammerickx et al., 1987), ya que solo cinco microlitros de sangre periférica inoculados por diferentes vías en forma experimental fueron suficientes para infectar a un bovino (González et al., 2001). Asimismo, el uso de las mismas agujas y jeringas, instrumentos quirúrgicos y/o guantes de tacto en diferentes animales es una causa potencial de transmisión del VLB en los rodeos (Kohara et al., 2006).

El control y la erradicación de la LEB se basan en la detección de animales seropositivos para VLB mediante diferentes pruebas inmunodiagnósticas. La prueba de inmunodifusión en gel de agar (IDGA) y la prueba de ELISA, son las oficiales y más utilizadas en los programas de control y erradicación de la enfermedad. La simplicidad en la realización, la fiabilidad y los bajos costos operativos para llevar a cabo la prueba de IDGA han sido determinantes en su elección en estudios epidemiológicos a nivel mundial. En nuestro país, mediante Resolución 337/94, el Servicio Nacional de Sanidad Animal y Calidad Agroalimentaria (SENASA) reglamentó el sistema de certificación de establecimientos libres de LEB. A partir de la aceptación voluntaria del productor, el mismo puede inscribir su rodeo en un esquema de certificación oficial que le otorgue y mantenga la condición libre de la enfermedad (de la Sota, 2005).

El área de influencia de la ZDRS abarca más de 6 millones de hectáreas. El stock de terneros representa el $16,05 \%$ de las existencias nacionales y el $34,03 \%$ de las provinciales, convirtiéndola en la principal zona donde se crian terneros de Argentina.

Debido a que no se conocen datos oficiales sobre la situación epidemiológica de LEB en bovinos de cría en la ZDRS, el objetivo de este trabajo fue determinar la seroprevalencia de infección por VLB en esta región y compararla con las registradas en otras regiones del país.

\section{Materiales y métodos}

Para el muestreo se utilizó la lista codificada de todos los establecimientos que integran la ZDRS. Se seleccionaron 90 establecimientos, cubriendo más del $85 \%$ de la región, con un total de 1957 bovinos. Las muestras fueron tomadas sobre la base de los resultados obtenidos con el programa estadístico ProMESA (Programme for Statistical Sampling in Animal Population) utilizando un nivel de confianza del $95 \%$ y un error relativo del $15 \%$. Los animales fueron divididos en tres categorías: terneros entre 6 a 12 meses, vaquillonas entre 12 y 24 meses y adultos mayores de 24 meses.

De cada animal se extrajeron $10 \mathrm{ml}$ de sangre sin anticoagulante de las venas yugular o coccígea media, utilizando agujas y jeringas individuales estériles. Una vez obtenido el suero, las muestras se transfirieron a tubos de $1,5 \mathrm{ml}$ y se mantuvieron a $-20^{\circ} \mathrm{C}$.

Para la detección de anticuerpos contra el VLB se utilizaron equipos de IDGA producidos en el Laboratorio de Virología de la Facultad de Ciencias Veterinarias de la Universidad Nacional de La Plata. Este equipo cuenta con la aprobación de SENASA (Expte. SENASA 40285/87, Cert. 88494), prueba oficial para la certificación de animales libres del VLB.

\section{Resultados}

Los resultados obtenidos de la lectura de las placas de IDGA demostraron que, de los 90 establecimientos, 6 presentaron al menos, un animal positivo a LEB, determinándose una prevalencia del $6,6 \%$. Sin embargo, para un total de 1957 sueros, 7 animales pertenecientes todos a la categoría de bovinos mayores de 24 meses fueron positivos para LEB. Sobre la base de estos resultados se obtuvo una prevalencia poblacional del $0,36 \%$ (Tabla 1 ).

\section{Discusión}

Diferentes estudios sobre seroprevalencia de infección por VLB se han llevado a cabo en varios países, sobre todo en aquellos que emplearon políticas de erradicación de la enfermedad. La prueba de IDGA, realizada en condiciones óptimas, es la técnica inmunológica más utilizada para el diagnóstico de LEB, debido a su bajo costo, fácil realización y elevada 
Tabla 1. Seroprevalencia de infección por el virus de leucosis enzoótica bovina (LEB) en la Zona Deprimida del Río Salado (ZDRS)

\begin{tabular}{|l|c|c|c|}
\hline \multicolumn{1}{c}{$\begin{array}{c}\text { Categoría de } \\
\text { animales }\end{array}$} & $\begin{array}{c}\text { Cantidad de } \\
\text { animales por } \\
\text { categoría }\end{array}$ & $\begin{array}{c}\text { Animales } \\
\text { positivos para } \\
\text { VLB }\end{array}$ & $\begin{array}{c}\text { Seroprevalencia } \\
\text { de infección por el } \\
\text { virus de LEB (\%) }\end{array}$ \\
\hline $\begin{array}{l}\text { Terneros entre 6 y } \\
12 \text { meses }\end{array}$ & 620 & - & - \\
\hline $\begin{array}{l}\text { Vaquillonas entre } \\
12 \text { y 24 meses }\end{array}$ & 410 & - & - \\
\hline $\begin{array}{l}\text { Adultos mayores } \\
\text { de 24 meses }\end{array}$ & 927 & 7 & $0,75 \%$ \\
\hline Total & 1957 & 7 & $\mathbf{0 , 3 6 \%}$ \\
\hline
\end{tabular}

especificidad. Sin embargo, esta técnica posee una sensibilidad media que la hace no muy adecuada para utilizar en estrategias de control de enfermedades de baja prevalencia (Trabattoni \& Moriondo, 2016) en las que se sugiere el uso de una técnica más sensible como el ELISA (Furtado et al., 2013; Nava et al., 2012).

Los últimos estudios de prevalencia en rodeos de cría de la provincia de Buenos Aires se realizaron hace más de 20 años. Además, estos estudios incluyeron diferentes provincias del centro y del norte de Argentina, como Córdoba, Entre Ríos, Formosa y La Pampa: se encontró una prevalencia del $1,8 \%$, con un rango de variabilidad entre el $0 \%$ para la provincia de La Pampa y el 9,7\% para la provincia de Formosa (Huici et al., 1997). La prevalencia en rodeos de cría en la Patagonia Argentina fue comunicada por Huici et al. (1995) y por Layana et al.(1997) y en Tierra del Fuego por Disalvo et al. (2016). Estos estudios revelaron valores del $0 \%$ de prevalencia, demostrando la ausencia de circulación viral en estas regiones. Reportes realizados por Resoagli et al. (2001) sobre prevalencia de LEB en los años 1998-1999 en el noroeste de la provincia de Corrientes mostraron una prevalencia del $11,8 \%$, de un total de 1093 muestras analizadas. En el año 2004, en la provincia de la Pampa se encontró una prevalencia poblacional del 0,17\% y el $10 \%$ de los rebaños analizados con, al menos, un animal positivo (Álvarez Rubianes, 2004). En 2016 Trabattoni y Moriondo encontraron una prevalencia total de $11,97 \%$ en un rodeo de cría del norte de la provincia de Santa $\mathrm{Fe}$, porcentaje que fue reducido a $3,91 \%$ luego de la eliminación de animales positivos. Si bien existen informes de diferencias en la prevalencia según el tamaño de los rodeos estudiados (Grau \& Monti, 2010), en este trabajo se carece de ese dato. Los resultados encontrados en nuestro trabajo, que incluyó el $85 \%$ de la superficie de la ZDRS, revelan que la prevalencia de infección por VLB en rodeos de cría se mantiene en el rango encontrado por Huici et al. (1997) demostrando que, en 20 años, no hubo cambios significativos en la misma y, hasta nuestro conocimiento, sin haber tomado medidas tendientes a su eliminación.

\section{Conclusiones}

Debido que la ZDRS es la región de mayor productividad de terneros de cría en Argentina, es de sumo interés determinar seroprevalencia para establecer zonas libres de LEB. Los resultados obtenidos permiten inferir el bajo impacto de la enfermedad en los rodeos de cría en la zona analizada.

\section{Agradecimientos}

Se agradece la colaboración de los entes sanitarios de los partidos participantes en el muestreo y la asistencia técnica-administrativa de la Sra. Adriana Conde y del Sr. Claudio Leguizamón de la Cátedra de Virología de la Facultad de Ciencias Veterinarias de la Universidad Nacional de La Plata. Este estudio fue subsidiado a través de un convenio firmado por el INTA y el Ministerio de Agroindustria de la provincia de Buenos Aires y también por la Secretaria de Ciencia y Técnica de la Universidad Nacional de La Plata (Proyecto 11-V221 parte I y II).

\section{Conflicto de intereses}

Todos los autores declaran que no existe conflicto de intereses, incluyendo las relaciones financieras, personales o de otro tipo con otras personas $u$ instituciones que pudieran influir de manera inapropiada en el trabajo.

\section{Bibliografía}

Álvarez Rubianes N. 2004. Leucosis enzoótica bovina: estudios seroepidemiológicos en rebaños de cría de la provincia de La Pampa-Argentina. Ciencias Veterinarias. 6(1):1-12.

Burny A, Cleuter Y, Kettmann R, Mammerickx M, Marbaix G, Portetelle D, VandenBroeke A, Willems L, Thomas R. 1988. Bovine leukaemia: facts and hypotheses derived from the study of an infectious cancer. Veterinary Microbiology. 17(3):197-218.

De la Sota MD. 2005. Manual de procedimientos de leucosis enzoótica bovina. Dirección Nacional de Sanidad Animal. Buenos Aires. Disponible en: www.intranet.senasa.gov.ar [consultado 10/05/2016].

Disalvo VN, Escribano C, Trono K. 2016. Diagnóstico serológico de leucosis enzoótica bovina en rodeos de cría de la provincia de Tierra del Fuego. Boletín INTA. 1-5. Disponible en: www.inta.gov.ar/documentos/diagnostico-serologico-deleucosis-enzootica-bovina-en-rodeos-de-cria-de-la-provincia-de-tierra-del-fuego [Consultado 01/01/2016].

Furtado A, Rosadilla D, Franco G, Piaggio J, Puentes R. 2013. Leucosis bovina enzoótica en cuencas lecheras de productores familiares de Uruguay. Veterinaria Montevideo. 49(191):29-37. 


\section{Panei CJ et al.}

González ET, Oliva GA, Valera A, Bonzo E, Licursi M, Etcheverrigaray ME. 2001. Leucosis enzoótica bovina: evaluación de técnicas de diagnóstico (ID, ELISA-I, WB, $\mathrm{PCR}$ ) en bovinos inoculados experimentalmente. Analecta Veterinaria. 21(2):12-20.

Grau MA, Monti G. 2010. Prevalencia serológica predial e intrapredial para el virus de la leucosis bovina (VLB) en lecherías de las regiones de los ríos y de los lagos de Chile. Archivos de Medicina Veterinaria. 42:87-91.

Hopkins SG, Di Giacomo RF. 1997. Natural transmission of bovine leukemia virus in dairy and beef cattle. The Veterinary Clinics of North America. Food Animal Practice. 13(1):107-28.

Huici NC, Segade G, Ramirez V, Gonzalez Gentile A. 1995. Diagnóstico serológico de leucosis enzoótica bovina en la Patagonia. Veterinaria Argentina. XII(115):303-5.

Huici N, Segade G, Ramírez V. 1997. Diagnóstico de leucosisenzoótica bovina en un rodeo carnicero de exportación: 1989-1994. Veterinaria Argentina. 14(131):26-31.

Kohara J, Konnai S, Onuma M. 2006. Experimental transmission of bovine leukemia virus in cattle via rectal palpation. Japanese Journal of Veterinary Research. 54(1):25-30.

Layana J, González N, Moreira AS, Vaghi CF. 1997. Encuesta serológica sobre brucelosis, leucosis y paratuberculosis bovinas en el Noroeste de la provincia de Río Negro, Argentina. Veterinaria Argentina. 14:83-90.

Mammerickx M, Portetelle D, De Clercq K, Burny A. 1987. Experimental transmission of enzootic bovine leukosis to cattle, sheep and goats: infectious doses of blood and incubation period of the disease. Leukemia Research. 11(4):353-8.

Nava Z, Obando C, Bracamonte M, Sousa A, Hidalgo M. 2012. Evaluación de la eficacia de la prueba de inmunodifusión en gel de agar para la detección de anticuerpos contra el virus de la leucosis enzoótica bovina. Revista de la Facultad de Ciencias Veterinarias de la UCV. 53(1):21-7.

Panei CJ, Takeshima SN, Omori T, Nunoya T, Davis WC, Ishizaki H, Matoba K, Aida Y. 2013. Estimation of bovine leukemia virus (BLV) proviral load harbored by lymphocyte subpopulations in BLV-infected cattle at the subclinical stage of enzootic bovine leucosis using BLV-CoCoMo-qPCR. BMC Veterinary Research. 4(9):95-102.

Resoagli JP, Jacobo RA, Storani CA, Cipolini, MF, Stamatti, GM, Deco M, Alfonso D. 2001. Seroprevalencia de leucosis enzoótica bovina en rodeos de cría de la provincia de Corrientes. Revista de Medicina Veterinaria. 82(2):71-3.

Trabattoni EM, Moriondo A. 2016. Leucosis bovina enzoótica en un rodeo de cría. Veterinaria Argentina. XXXIII(337):1-6. 